\title{
Uma releitura da recepção de Mestre Eckhart por Heidegger à luz dos
}

Cadernos negros

\section{Eine Relektüre von Heideggers Rezeption Meister Eckharts im Lichte der Schwarzen Hefte}

DOI: 10.12957/ek.2021.56819

\section{Ricardo Baeza García ${ }^{1}$}

Philosophisches Seminar / Albert-Ludwigs-Universität Freiburg ricardo.baeza74@hotmail.com

\section{Referência original da publicação:}

BAEZA, Ricardo. Eine Relektüre von Heideggers Rezeption Meister Eckharts im Lichte der Schwarzen Hefte. Maxime Mauriège und Martina Roesner (Hrsg.). Meister Eckharts Rezeption im Dritten Reich. Brill, Leiden, im Druck 2022.

\section{Tradução, revisão e notas:}

\section{Luís Gabriel Provinciatto ${ }^{2}$}

Universidade de Évora / UFJF

lgprovinciatto@hotmail.com

https://orcid.org/0000-0003-0597-8641
Deborah Moreira Guimarães ${ }^{3}$

Universidade Federal de São Paulo deborahmoreiraguimaraes@gmail.com http://orcid.org/0000-0003-2459-9559

\footnotetext{
${ }^{1}$ Ricardo Baeza García é filósofo, doutor em filosofia pela Universidade de Freiburg e professor contratado na mesma instituição. Pesquisa temas relacionados à fenomenologia, sobretudo, em sua aproximação com autores da tradição metafísica medieval.

2 Doutorando em Filosofia pela Universidade de Évora e doutorando em Ciência da Religião pela Universidade Federal de Juiz de Fora. Áreas de interesse: fenomenologia, metafísica e ciências da religião.

${ }^{3}$ É mestre e doutora em Filosofia pela UNIFESP. Áreas de interesse: fenomenologia, hermenêutica e metafísica.

* Agradecemos ao Professor Dr. Ricardo Baeza García pela gentileza em compor conosco a presente edição, remetendo-nos este artigo e os seus direitos autorais para republicarmos a sua tradução na Ekstasis. Na edição do artigo, decidimos manter as citações conforme o material que nos foi originalmente enviado. No entanto, foi necessário padronizar alguns aspectos pré-textuais e formais, como a inserção do resumo e das palavras-chave, e a formatação geral do texto. As referências bibliográficas serão mantidas conforme o manuscrito original: nas notas de rodapé.
} 


\title{
RESUMO
}

Este artigo tem como objetivo principal explicitar uma nova possibilidade de interpretação da recepção de Mestre Eckhart por Heidegger. Esse intuito será realizado a partir, sobretudo, dos desdobramentos gerados pela publicação recente dos Cadernos negros, marco extremamente relevante no âmbito da filosofia heideggeriana e de sua recepção.

Palavras-chave: Heidegger. Mestre Eckhart. Cadernos negros.

\begin{abstract}
This article has as main objective to explain a new possibility of interpretation of the reception of Mestre Eckhart by Heidegger. This intention will be achieved starting, above all, from the unfolding generated by the recent publication of Black Notebooks, an extremely relevant landmark within the scope of Heidegger's philosophy and its reception.
\end{abstract}

Keywords: Heidegger. Master Eckhart. Black Notebooks.

A publicação dos primeiros volumes dos Cadernos negros, em 2014, reavivou a controvérsia da relação de Heidegger com o nacional-socialismo. Antes da publicação dos Cadernos negros, as declarações de Heidegger após a Segunda Guerra Mundial foram contidas e ambíguas. ${ }^{4}$

\footnotetext{
${ }^{4}$ Sobre os comentários mesmos de Heidegger a respeito de sua própria posição, veja: HEIDEGGER, Martin. Das Rektorat 1933/34 - Tatsachen und Gedanken (1945), Reden und andere Zeugnisse. Frankfurt am Main, 2000, pp. 372-394. HEIDEGGER, Martin. Antrag auf die Wiedereinstellung in die Lehrtätigkeit - Reintegrierung (November 4, 1945), Reden und andere Zeugnisse, Frankfurt am Main, 2000, pp. 397-404. HEIDEGGER, Martin. Spiegel-Gespräch mit Martin Heidegger (September 26, 1966), Reden und andere Zeugnisse, Frankfurt am Main, 2000, pp. 652-683. Quanto ao engajamento de Heidegger como reitor da Universidade de Freiburg em 1933 e o aparecimento dos Cadernos negros, Hans-Helmuth Gander, em seu prefácio para a antologia Heideggers Weg in die Moderne. Eine Verortung der "Schwarzen Hefte", diz: "em todo caso, desde os anos 1950, as pessoas questionavam repetidamente se o engajamento de Heidegger como reitor da Universidade de Freiburg se deveu, de fato, à ingenuidade de um filósofo. Isso definitivamente não é mais possível". No debate atual sobre a própria posição política de Heidegger, ainda há intérpretes que querem retratar uma tal "ingenuidade do filósofo". GANDER, Hans-Helmuth. Prefácio de: GANDER, Hans Helmuth; STRIET, Marcus (Hrsg.), Heideggers Weg in die Moderne. Eine Verortung der "Schwarzen Hefte", Frankfurt am Main, 2017, p. 7. Nesse sentido, Jean Grondin diz: "Heidegger foi um pensador notável e brilhante, sua obra filosófica e sua história de impacto mundial [weltweite Wirkungsgeschichte] confirmam muito isso, politicamente, contudo, ele foi completamente sem talento (reconhecidamente o eufemismo do século). Ele possuía e demonstrava uma sólida formação filosófica, mas nunca uma política, ao contrário. Ele foi um teórico pioneiro do nosso "ser-no-mundo", no entanto, dispunha de uma experiência muito limitada do mundo.
} 
A questão permanece: em que medida outros autores, que, para Heidegger, desempenharam um papel importante na História da Filosofia, ou autores que até apresentaram traços não-metafísicos, representam, para Heidegger, um "pensamento antijudaico”. Nesse sentido, a mística de Mestre Eckhart será aqui analisada com vistas a mostrar que, após a publicação dos Cadernos negros, é possível uma nova leitura sobre a recepção de Mestre Eckhart por Heidegger.

\section{O conceito heideggeriano de metafísica}

Os chamados Cadernos negros são manuscritos que Heidegger redigiu de 1931 até início dos anos 1970. Os Cadernos negros do Terceiro Reich já foram publicados, e a publicação dos três primeiros volumes, em março de 2014, abriu uma nova perspectiva quanto à interpretação heideggeriana do movimento nacional-socialista. Um tema central dos Cadernos negros é o desenvolvimento onto-histórico da metafísica [die seinsgeschichtliche Entfaltung der Metaphysik], que se fundamenta em uma determinada interpretação da diferença ontológica. Esse tema é central para a filosofia de Heidegger a partir dos anos 1930. Nos Cadernos negros também se encontram implicações políticas, que são determinadas pelo desenvolvimento da metafísica enquanto tal. A ontologia de Heidegger está, portanto, essencialmente ligada a uma perspectiva política. Para compreender as implicações políticas, deve-se, em primeiro lugar, explicar o que Heidegger compreende por metafísica e "pensar calculador" [rechnendem Denken]. No interior dessa análise, o pensamento de Mestre Eckhart também será tematizado.

Heidegger emprega o conceito de serenidade [Gelassenheit] de Mestre Eckhart para se referir à essência do ser humano. Essa [essência], contudo, escondeu-se atrás das interpretações derivadas e tradicionais do ser humano. Para Heidegger, as interpretações tradicionais ou metafísicas configuram, portanto, o entrave para descobrir a essência

Ele teve a infelicidade de crescer e se tornar filosoficamente significativo em uma época em que a Alemanha perdeu uma guerra mundial e sofreu gravemente com as consequências políticas, espirituais e econômicas dessa derrota". HOMOLKA, Walter; HEIDEGGER, Arnulf (Hrsg.). Heidegger und der Antisemitismus: Positionen im Widerstreit, Freiburg, 2016, p. 232. Friedrich-Wilhelm von Herrmann (2014, p. 628) afirma que as declarações antissemitas de Heidegger nos Cadernos negros são "completamente irrelevantes e, portanto, supérfluas". von HERRMANN, Friedrich-Wilhelm. "Kein systematischer Baustein des Denkens - philosophisch belanglos". Meta: Research in Hermeneutics, Phenomenology and Practical Philosophy, v. VI, n. 2, Iasi, 2014, p. 638. 
originária do ser humano. Assim, procura-se apreender a essência do ser humano "sem olhar para o ser humano". 5

Segundo Heidegger, a origem do pensar como querer encontra-se no início da filosofia ocidental ou do pensamento metafísico. O início do pensamento metafísico está ligado ao domínio do pensamento representativo-volitivo. A resposta platônica à pergunta sobre o ser determinou sua aparência mesma como algo. Nesse sentido, Heidegger diz: "ao longo de toda a História da Filosofia, o pensamento de Platão, ainda que em diferentes formas, permanece determinante. A metafísica é platonismo". ${ }^{6}$

Dessa maneira, a metafísica é o desenvolvimento do nada negativo, ou seja, a negação total do ente que está presente. ${ }^{7}$

\begin{abstract}
E se o nada, na verdade, não fosse, porém, um ente, mas tampouco nunca algo apenas nulo? E se a pergunta sobre a essência do nada, com o auxílio daquele $o u-o u$, não fosse ainda suficientemente colocada? E, ainda mais, se a ausência dessa pergunta desenvolvida acerca da essência do nada for o fundamento para o fato de a metafísica ocidental dever se tornar a presa do niilismo? Experienciado e concebido de uma maneira mais originária e mais essencial, o niilismo seria, então, aquela História da Metafísica que impele para uma posição metafísica fundamental, na qual o nada não apenas não pode ser compreendido em sua essência, mas tampouco quer ser mais concebido. Niilismo significaria, então: o essencial não-pensar na essência do nada. ${ }^{8}$
\end{abstract}

Enquanto o pensamento metafísico se caracteriza pela pergunta pelo ser como algo, a pergunta pelo nada, em contrapartida, não procura algo, e, por isso, permanece fora do pensamento metafísico. O nada é aqui tampouco o apenas nulo. O nada contém o todo. Em Heidegger, esse antigo paradoxo místico tem a ver com o caráter aberto do nada, cujo "descerramento de todo o espaço da verdade" "antecede o ser-aí.

A consideração de Heidegger do conceito de nada tem muitas semelhanças com o pensamento de Eckhart, que compreende o nada não como algo abstrato, pensado em

\footnotetext{
${ }^{5}$ HEIDEGGER, Martin. Zur Erörterung der Gelassenheit. Aus der Erfahrung des Denkens 1910-1976, Frankfurt am Main, 1983, p. 38. "Niht enwil" (DW II, p. 488). As obras de Eckhart são citadas de acordo com a edição publicada por Josef Quint, especificando o volume e o número da página dos textos originais usando os símbolos DW [deutsches Werk] (obra alemã). Os escritos de Eckhart são citados no texto principal após a tradução de Josef Quint. Os textos originalmente escritos em alto médio alemão são reproduzidos nas notas de rodapé por uma questão de rigor filológico. "Contudo, todo perguntar é um modo de ouvir e, principalmente, uma forma de querer ouvir”. HEIDEGGER, Martin. Ein Gespräch selbstdritt auf einem Feldweg. Feldweg Gespräche (1944-45), Frankfurt am Main, 1995, p. 25.

${ }^{6}$ HEIDEGGER, Martin. Zur Sache des Denkens, Tübingen, 1969, p. 71.

${ }^{7}$ HEIDEGGER, Martin. Beiträge zur Philosophie: vom Ereignis, Frankfurt am Main, 1989, p 246. HEIDEGGER, Martin. ,,Was ist Metaphysik?“. Wegmarken, Frankfurt am Main, 1976, p. 122.

${ }^{8}$ HEIDEGGER, Martin. Nietzsche, v. II, Stuttgart, 1961, p. 44.

${ }^{9}$ HEIDEGGER, Martin. ,,Was ist Metaphysik? “. Wegmarken, Frankfurt am Main, 1976, p. 121.
} 
contraposição ao ser. Ao contrário, para Heidegger tanto quanto para Eckhart, o nada pertence ao ser. ${ }^{10}$

\section{Os Cadernos negros e a nova perspectiva política}

A problemática da tentativa de superar a metafisica enquanto tal não tem, a princípio, relação com perspectivas políticas. Apesar disso, Karl Löwith, em sua biografia, relata um encontro com Heidegger em Roma, em 1936. Na época, Heidegger lhe teria dito que o Nazismo seria a expressão mais profunda de seus princípios filosóficos, conforme eles estariam apresentados em Ser e tempo. Para Löwith, Heidegger tampouco deixou dúvidas a respeito de Hitler. ${ }^{11}$

Esta é, porém, a razão para o aumento temporário do poder do judaísmo: a metafísica do Ocidente, sobretudo em seu desdobramento moderno, ofereceu o ponto de partida para a expansão de uma racionalidade e de uma capacidade de cálculo [Rechenfähigkeit] vazias, que, por esse caminho, se proporcionaram um abrigo no "espírito", sem poderem apreender por si mesmas os âmbitos ocultos de decisão. Quanto mais originárias e mais iniciais forem as decisões e as perguntas futuras, tanto mais inacessíveis elas permanecerão a essa "raça"".

A "racionalidade vazia" aponta para um modo especial de objetivação [Vergegenständlichung] do ente, que se desenvolve por meio da matemática e do “pensar calculador”. Heidegger atribui essa capacidade de cálculo vazia ao judaísmo. Contudo, essa não é a origem do pensamento metafísico. A metafísica "usou" o judaísmo para desenvolver seu domínio enquanto "racionalidade e capacidade de cálculo vazias" em seu último estágio ${ }^{13}$.

Meu "ataque" contra Husserl não se dirige apenas contra ele e, em geral, de modo circunstancial - o ataque vai contra a omissão da pergunta pelo ser, ou seja, contra a essência da metafísica enquanto tal, sobre cujo fundamento a

10 Abandonar-se no nada e dar espaço ao ente na totalidade (Ibid., p. 122). Veja, ainda: BAEZA, Ricardo. Die Topologie des Ursprungs. Der Begriff der Gelassenheit bei Eckhart und Heidegger und seine Entfaltung in der abendländischen Mystik und im zeitgenössischen Denken, Berlin 2009, pp. 81-82.

${ }^{11}$ LÖWITH, Karl. Mein Leben in Deutschland vor und nach 1933, Stuttgart, 1986, p. 57

${ }^{12}$ HEIDEGGER, Martin. Überlegungen XII-XV (Schwarze Hefte 1939-1941), Frankfurt am Main, 2014, p. 46.

${ }^{13}$ Nesse sentido, Johannes Fritsche diz: “toda verdade epocal, no entanto, precisa do ser humano, precisa de uma determinada concreção humana [Menschentümlichkeit], só a partir da qual ela se essencia. Se, a partir do destino [Geschick], investiga-se a verdade destinada [geschickt Wahrheit] da Era Moderna e a concreção humana reivindicada por essa verdade e se compara os seres humanos e as raças com ambos, então, ter-se-á que perceber, de acordo com Heidegger, que a verdade da Era Moderna reivindica precisamente a concreção humana que os judeus foram os únicos a praticar muito antes da Era Moderna". FRITSCHE, Johannes. "Jüdisches und griechisch-deutsches Rechnen bei Heidegger". Martin Heidegger "Schwarze Hefte”. Eine philosophisch-politische Debatte, Berlin, 2016, p. 204. 
maquinação do ente pode determinar a história. $\mathrm{O}$ ataque funda um instante histórico [geschichtlich Augenblick] da mais alta decisão entre a primazia do ente e a fundamentação da verdade do seer $[\text { Seyn }]^{14}$.

A primazia do ente é pensada antecipadamente nos Cadernos negros como desenvolvimento onto-histórico, que deve culminar em uma absoluta falta de destinação e uma total confusão ontológica. Heidegger diz:

Quando a falta-de-destinação [Ziel-losigkeit] do ser humano se consumar
(quando já só se colocarem fins no interior do ente e os meios de realização,
os caminhos e os empreendimentos mesmos se tornarem "os" fins, e,
consequentemente, seu cumprimento conceder sempre mais fácil e
definitivamente a satisfação de todas as reivindicações, e, assim, as próprias
reivindicações se permitirem estar, cada vez mais, em um plano prévio e
"mais próximas da vida"), então o ser humano, inesperadamente e sem
perceber nada, tornar-se-á o beneficiário de uma grande destruição, que lhe
acontecerá como uma gigantesca construção ${ }^{15}$.

Pensava-se aqui no fim e no novo início, que não deve ser compreendido como “interrupção", mas, sim, como "um começo próprio, que, entretanto, permanece privado de si mesmo em sua verdade" 16 .

E talvez nesta "luta", na qual se luta pela falta de objetivo pura e simplesmente e que, portanto, só pode ser uma caricatura da "luta", "triunfe" a maior falta de solo [Bodenlosigkeit], que, sem se vincular a nada, põe tudo a seu serviço (o judaísmo). Mas o triunfo autêntico, o triunfo da história sobre o sem-história, só é alcançado aí onde o sem solo [Bodenlose] se exclui a si mesmo, porque ele não arrisca o seer [Seyn], mas sempre apenas conta com o ente e põe seus cálculos como o real ${ }^{17}$.

Em Heidegger, o conceito de "raça" tem uma dimensão metafísica que permanece distante das considerações meramente biológicas e materialistas. Nesse sentido, Heidegger diz o seguinte nos Cadernos negros:

Por seu talento calculador acentuado, os judeus já "vivem” há muito tempo de acordo com o princípio racial, razão pela qual são também os que mais duramente se opõem à sua aplicação irrestrita. A instituição da criação racial não surge da "vida" mesma, mas da sobre-predominância [Übermächtigung] da vida por meio da maquinação. Esta opera, com tal plano, uma desracialização total [vollständige Entrassung] dos povos por meio da restrição deles mesmos em uma instituição igualmente construída e nivelada de todo ente. Com a desracialização, dá-se uma autoalienação [Selbstentfremdung] dos povos - a perda da história -, ou seja, [uma perda] dos âmbitos de decisão a respeito do seer $[\operatorname{Seyn}]^{18}$.

14 HEIDEGGER, Martin. Überlegungen XII-XV (Schwarze Hefte 1939-1941), Frankfurt am Main: Vittorio Klostermann, 2014, p. 46.

${ }^{15}$ HEIDEGGER, Martin. Überlegungen VII-XI (Schwarze Hefte 1938-1939), Frankfurt am Main: Vittorio Klostermann, 2014, p. 182.

${ }^{16}$ Ibid., p. 96.

${ }^{17}$ Ibid., pp. 96-97.

18 HEIDEGGER, Martin. Überlegungen XII-XV (Schwarze Hefte 1939-1941), Frankfurt am Main: Vittorio Klostermann, 2014, p. 56. 
O uso que Heidegger faz do conceito de "raça" é de caráter ambivalente. A interpretação negativa se fundamenta em uma biologização superficial como resultado do conceito moderno de sujeito. ${ }^{19}$

Um tal uso do conceito de "raça" era comum ao longo do século XIX e no início do século XX em todas as correntes ideológicas. Tais afirmações em disciplinas como antropologia ou etnologia se fundamentam em uma interpretação metafísica do ser humano como sujeito, interpretação da qual Heidegger se distancia.

Se tomarmos por fundamento a determinação essencial do ser humano como ser$a i$, que, desde Ser e tempo, permaneceu decisiva para Heidegger, põe-se a pergunta de como se pode aqui traçar significativamente um conceito positivo de "raça". Em primeiro lugar, é importante observar que os conceitos de "raça" e de "povo" estão relacionados a uma interpretação positiva da constituição linguística. O parentesco da língua grega com a língua alemã já ocupava um lugar [Topos] central no Romantismo. ${ }^{20}$

Em contraposição ao judaísmo, que, como "pensar calculador", representa a degenerescência [Unwesen $]^{21}$ do ser humano, Heidegger vê nos gregos e nos alemães os povos do início e da superação da metafísica. ${ }^{22}$

Em sua preleção de 1934 sobre a lógica como pergunta pela essência da linguagem, Heidegger diz o seguinte sobre o conceito de "raça":

Frequentemente, usamos a palavra "povo" também no sentido de "raça" (também, por exemplo, no uso da expressão "movimento nacional"). O que

\footnotetext{
19 “Ao contrário do jovem Scheler e de outros direitos, a pergunta pelo papel do "judaísmo mundial” não é racial, pois não se pode respondê-la salientando que a raça dos judeus alcançou o poder mundial por meio da mistura de sangue e de outros processos ônticos. Antes, deve-se perguntar metafísica ou ontologicamente sobre qual modo de desencobrimento, de verdade, de destino enviou para a Era Moderna, pois é a respectiva verdade epocal que define o espaço de jogo [Spielraum] para o ser humano". FRITSCHE, Johannes. Jüdisches und griechisch-deutsches Rechnen bei Heidegger. Martin Heidegger "Schwarze Hefte”. Eine philosophisch-politische Debatte, Berlin, 2016, p. 204.

20 A respeito do parentesco das línguas grega e alemã, ver: SCHLEGEL, Friedrich. Über deutsche Sprache und Literatur. Schlegel diz aí: "de todas os novos idiomas europeus, o alemão é o mais rico"; e ainda: "o alemão (...), de todos os outros idiomas europeus, é o que mais tem em comum com o grego". SCHLEGEL, Friedrich. Über deutsche Sprache und Literatur, Darmstadt, 2006, pp. 4-7.

${ }^{21}$ [N.T.]: O termo Unwesen possui correspondência direta com o termo Wesen, geralmente traduzido por essência. No entanto, gostaríamos de destacar que há um sentido mais preciso e comum para Unwesen na língua alemã, em contextos gerais. Trata-se da noção de que algo está em desordem, isto é, trata-se de um estado ruim de coisas. Assim, acreditamos que o termo "degenerescência" retrata bem aquilo que está em jogo neste contexto: a noção de "desmedida" (Unfug), isto é, de desordem, inclusive metafísica.

22 "Aos gregos foi dada a estimulante proximidade em relação ao fogo do céu, o ser-afetado [Betroffenwerden] pela violência do seer [Seyn]. A eles coube a tarefa da domesticação do indomado na conquista da obra, o conceber, trazer-à-posição [Zum-Stand-bringen]. Aos alemães foi dado: o saberconceber [Fassenkönnen], a preparação e o planejamento dos domínios e das áreas, o ordenamento para a organização. A eles coube a tarefa de ser-afetados pelo seer [Seyn]". HEIDEGGER, Martin. Hölderlins Hymnen "Germanien” und "Der Rhein”, Frankfurt am Main, 1999, pp. 292-293.
} 
chamamos de "raça" tem uma relação com o contexto corporal, sanguíneo, dos elementos do povo, da sua linhagem. A palavra e o conceito de "raça" não são menos ambíguos que "povo". (...) "Raça" não significa apenas racial [Rassiches], como laços de sangue, no sentido da hereditariedade, da consanguinidade e do impulso da vida, mas também significa, ao mesmo tempo e frequentemente, a raça nobre [das Rassige]. Mas isso não é limitado à condição corporal, pois também dizemos, por exemplo, "carro de raça" (pelo menos os jovens). A raça nobre ocupa uma determinada posição, faz certas leis, não visa, em primeira linha, a corporeidade da família e dos gêneros. Racial, no primeiro sentido, não necessita mesmo ser de raça nobre, podendo, antes, ser inteiramente sem-raça [unrassig $]^{23}$.

Por "racial", entende-se aqui a consideração de "raça" como um fato biológico.

Em contrapartida, "raça" aponta para um estado espiritual associado a um significado positivo e essencial. Portanto, a "desracialização" tem menos implicações biológicas que, ao contrário, espirituais. A “desracialização", pensada de modo onto-histórico, é um aspecto essencial do último estágio do desenvolvimento da metafísica. Para Heidegger, a luta exige "sangue e solo" como aquelas forças que, com o conhecimento e com o espírito, formam as condições para o ser-aí de um povo ${ }^{24}$.

Para Heidegger, o deus judaico exerceu seu próprio domínio como "totalitarismo" contra essa posição originária grega ou europeia. Desse modo, conforme Heidegger, os sistemas modernos de total ditadura provêm do monoteísmo judaicocristão ${ }^{25}$.

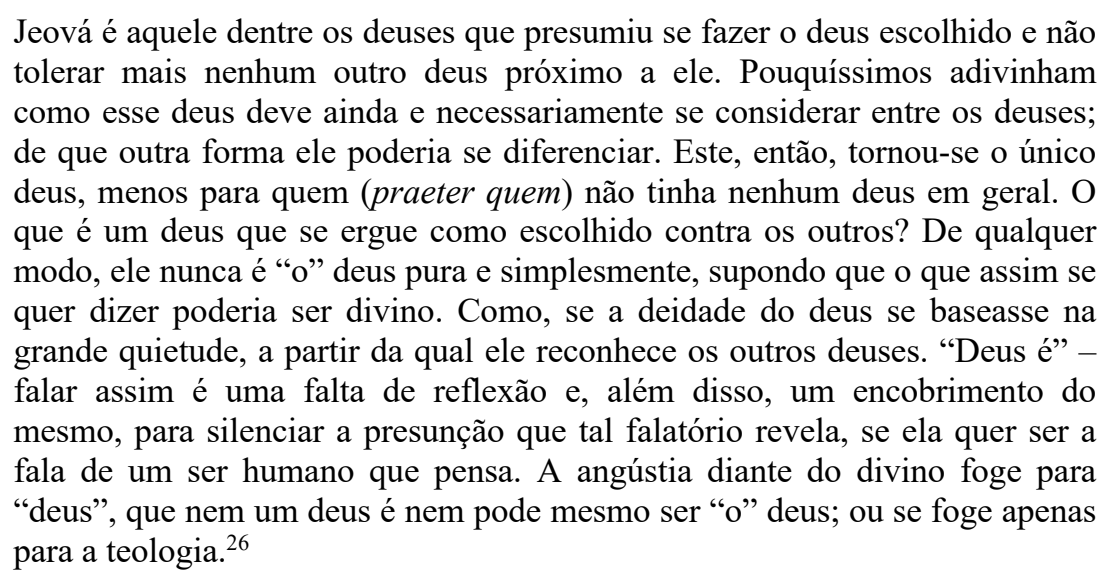

Pode-se encontrar aqui uma conexão evidente entre o pensamento de Heidegger e a tradição gnóstica. Para essa tradição, Jeová não é apenas nenhum deus, mas o falso

${ }^{23}$ HEIDEGGER, Martin. Logik als die Frage nach dem Wesen der Sprache, Frankfurt am Main: Vittorio Klostermann, 1998, p. 65.

${ }^{24}$ Ver HEIDEGGER, Martin. Sein und Wahrheit, Frankfurt am Main, 2001, p. 263. HEIDEGGER, Martin. Vom Wesen der Wahrheit. Sein und Wahrheit, Frankfurt am Main, 2001, p. 225.

${ }^{25}$ HEIDEGGER, Martin. Anmerkungen I-V (Schwarze Hefte 1942-1948), Frankfurt am Main, 2015, p. 438.

${ }^{26}$ Ibid., p. 369. 
deus ou o Demiurgo. Para Heidegger, Jeová corresponde à ausência de mundo [Weltlosigkeit] do judaísmo, a respeito da qual ele se expressou da seguinte maneira uma vez: "uma das formas mais encobertas do gigantesco, e talvez a mais antiga, é a tenaz habilidade de calcular e deslocar e misturar as coisas de forma confusa [Durcheinandermischens], o que fundamenta a ausência de mundo do judaísmo". ${ }^{27}$

Para Nietzsche, o que, de fato, aconteceu há dois milênios com o surgimento do cristianismo foi um acontecimento-apropriador [Ereignis] de vingança e de "ódio judeu". ${ }^{28}$

\section{As influências de Heidegger no interior do círculo nacional-socialista e a} importância de Mestre Eckhart

Por volta do final da década de 1920, Alfred Baeumler apresentou Nietzsche como o filósofo do nacional-socialismo. Heidegger interpretou Nietzsche em suas preleções, a partir de 1936, com a edição de Baeumler de $A$ vontade de poder. No semestre de inverno de 1936/1937, Heidegger, em suas preleções sobre Nietzsche, diz: “a Europa ainda quer se apegar à 'democracia' e não quer aprender a ver que esta seria sua morte histórica". ${ }^{29}$

Já em 1916, Heidegger escreve em uma carta para Elfride, sua futura esposa, que a "judaização" da cultura e das universidades na Alemanha era aterrorizante. ${ }^{30}$

Há aqui, em última análise, dois movimentos diametralmente opostos que contêm duas dimensões. O movimento para o si mesmo e o movimento para o desenraizamento. Para Heidegger, em seus Cadernos negros, a questão do papel do judaísmo mundial "não é racial, mas uma questão metafísica acerca do modo de ser de

\footnotetext{
${ }^{27}$ HEIDEGGER, Martin. Überlegungen VII-XI (Schwarze Hefte 1938-1939), Frankfurt am Main, 2014, p. 97. TRAWNY, Peter. Heidegger und der Mythos der jüdischen Weltverschwörung, Frankfurt am Main, 2014, p. 33. Ainda a esse respeito, cf.: HEINZ, Marion; KISIEL, Theodore. Heideggers Beziehungen zum Nietzsche-Archiv im Dritten Reich, SCHÄFER, Herrmann (Hrsg.), Annährungen an Martin Heidegger. Festschrift für Hugo Ott zum 65. Geburtstag, Frankfurt am Main, 1996, pp. 25-36.

${ }^{28}$ NIETZSCHE, Friedrich. Zur Genealogie der Moral, Berlin, 1968, p. 282.

${ }^{29}$ HEIDEGGER, Martin. Nietzsche: Der Wille zur Macht als Kunst, Frankfurt am Main, 1985, p. 193. HEIDEGGER, Martin. Überlegungen XII-XV (Schwarze Hefte 1939-1941), Frankfurt am Main, 2014, p. 243. Nesse sentido, Peter Trawny diz que, para Heidegger, o mundo judaico não possui outro objetivo que a destituição de todos os outros povos: "uma 'raça' que busca conscientemente a 'desracialização dos povos". TRAWNY, Peter. Heidegger und der Mythos der jüdischen Weltverschwörung, Frankfurt am Main, 2014, p. 67.

${ }^{30}$ HEIDEGGER, Gertrud (Hrsg.). Martin Heidegger: “Mein liebes Seelchen!”, München, 2005, p. 51.
} 
uma concreção humana [Menschentümlichkeit], ${ }^{31}$ que, sendo pura e simplesmente desvinculada, pode assumir como 'tarefa' histórico-mundial o desenraizamento de todo ente em relação ao ser". ${ }^{32}$

Nesse sentido, diz Heidegger nos Cadernos negros:

O judaísmo mundial, incitado pelos emigrantes a quem se permitiu sair da Alemanha, é inapreensível por toda parte e, apesar de todo o desenvolvimento de poder, não precisa jamais participar em ações bélicas, ao passo que nos resta sacrificar o melhor sangue do melhor de nosso povo. ${ }^{33}$

Não precisamos de técnica e política, cultura e moral, como destinações e elementos do seer-aí [Daseyn]. Esses instrumentos da metafísica se tornam obsoletos por meio da distorção da metafísica. Nós precisamos de mestres do saber que possam ensinar. (...) Saber é a insistência na verdade do seer [Seyn]. Experienciamos a verdade no pensar rememorante [Gedächtnis]. O pensar rememorante é a poesia [Dichtung]. ${ }^{34}$

Autores como Hölderlin, Heráclito ou Eckhart apontam para um movimento que leva ao si mesmo. Para Heidegger, eles são pensadores que não se deixam classificar no interior da tradição judaico-cristã. Dentro do movimento nacional-socialista, encontra-se uma interpretação similar do pensamento de Eckhart em Alfred Rosenberg. Em sua obra $O$ mito do século $X X$, Rosenberg liga Eckhart a uma posição heroica, que está longe do catolicismo. ${ }^{35}$

O deus que nós adoramos não existiria se nossa alma e nosso sangue não existissem; essa seria a confissão de um Mestre Eckhart para o nosso tempo. Portanto, é coisa de nossa religião, de nossos direitos, de nosso Estado, tudo o que protege, fortalece, purifica e faz prevalecer a honra e a liberdade desta alma e deste sangue. Portanto, lugares sagrados são todos aqueles onde heróis alemães morreram por esses ideais; sagrados são aqueles lugares onde pedras e monumentos memoriais os recordam; e dias sagrados são aqueles em que outrora eles lutaram mais apaixonadamente por tais causas. E a hora sagrada dos alemães chegará quando o símbolo do despertar, a bandeira com o sinal da vida em ascensão se tornar o único compromisso dominante do governo $\left[\right.$ Reich.$^{36}$

Características de uma interpretação biológica do conceito de raça são encontradas na obra de Rosenberg, que interpretou de maneira biológico-racista os

31 [N.T.]: O termo Menschentümlichkeit é um neologismo criado por Heidegger para se referir a uma espécie de destino ao qual a humanidade estaria submetida. Nesse sentido, trata-se da realização concreta de uma humanidade enquanto projeto próprio, autêntico (eigen), isto é, visa-se aqui a destinação daquilo que caracteriza a propriedade (Eigentum) da humanidade em seu solo.

32 HEIDEGGER, Martin. Überlegungen XII-XV (Schwarze Hefte 1939-1941), Frankfurt am Main, 2014, p. 243.

${ }^{33}$ HEIDEGGER, Martin. Überlegungen VII-XI (Schwarze Hefte 1938-1939), Frankfurt am Main, 2014, p. 338.

${ }^{34}$ HEIDEGGER, Martin. Zum Ereignis Denken, Frankfurt am Main, 2013, p. 703.

35 ROSENBERG, Alfred. Der Mythus des 20. Jahrhunderts. Eine Wertung der seelisch-geistigen Gestaltenkämpfe unserer Zeit, München, 1934, p. 138.

${ }^{36}$ HEIDEGGER, Martin. Zum Ereignis Denken, Frankfurt am Main, 2013, p. 701. 
conceitos "germânico" e "nórdico", usados pelos românticos alemães com conotações positivas. Particularmente dura é a crítica de Rosenberg ao catolicismo e à sua incorporação desdobrada na ordem jesuíta. Para Rosenberg, o jesuitismo alterou as últimas consequências do sistema romano. ${ }^{37}$

Fora da Alemanha, encontra-se a justificação de Eckhart no interior da constelação nacional-socialista de Julius Evola. Segundo Thomas Vaseck, há uma nota no manuscrito de Heidegger vinda literalmente do livro de Evola, Revolta contra o mundo moderno, publicado pela primeira vez em alemão em 1935. Embaixo está a seguinte frase:

Se uma raça perdeu o contato com aquilo que sozinho tem e pode dar estabilidade - com o mundo do seer [Seyn $]$ - então os organismos coletivos formados por ela, qualquer que seja seu tamanho e poder, fatalmente afundam no mundo da ocasionalidade. ${ }^{38}$

O conceito de "raça" é central na obra de Evola. Ele o tematiza em quase todos os seus escritos. Contudo, Evola adapta uma interpretação particular, que ele mesmo descreve como "racismo do espírito" [Rassismus des Geistes]. O "racismo do espírito" se diferencia das interpretações racistas, que têm a biologia como acesso metodológico. Esse tipo de racismo tem como fundamento filosófico a etnologia e a antropologia dos séculos XIX e XX, e tais teorias se degeneraram em um tipo de "supremacismo europeu" nos períodos tanto imperialista quanto nacional-socialista. O "racismo de espírito" tem como fundamento ontológico a doutrina do sangue. Segundo Evola, a memória do sangue é aquele axioma que pode formar uma identidade nacional. Racismo e antissemitismo são, para Evola, dois conceitos diferentes. Ser um antissemita tem a ver com o descobrimento de uma guerra espiritual e secreta, para a qual os Protocolos dos Sábios de Sião são usados como evidência. Esse livro era bem conhecido nos círculos antissemitas do século XX. ${ }^{39}$

\footnotetext{
37 ROSENBERG, Alfred. Der Mythus des 20. Jahrhunderts. Eine Wertung der seelisch-geistigen Gestaltenkämpfe unserer Zeit, München, 1934, p. 175.

${ }^{38}$ VASEK, Thomas. Ein spirituelles Umsturz-Programm, Frankfurter Allgemeine Zeitung, Dec. 2015, p. 32. Julius Evola, Rivolta contro il mondo moderno, Rom 1969, p. 148.

39 A respeito dos Protocolos, Julius Evola escreve: Nell'introduzione che scrissi per la ristampa, curata da Preziosi, dei famosi e discussissimi Protocolli dei Savi di Sion. Rilevai ciò̀ quanto fosse pericoloso credere che solo l'ebraismo sia il nemico da combattere: in tale credenza fui perfino propenso a vedere il risultato di una tattica di quella che io avevo chiamato la "guerra occulta". EVOLA, Julius. Il cammino del cinabro, Milan, 1963, pp. 174-175. [N.T.]: Citação em italiano, no original. "Na introdução que escrevi para a reimpressão, editada por Preziosi dos famosos e muito discutidos Protocolos dos Sábios de Sião. Isto é, observei como era perigoso crer que só o judaísmo fosse o inimigo a combater: nessa crença,
} 
De acordo com Evola, o povo judeu não é, estritamente, uma raça. Há diferentes povos cujo objetivo é aniquilar a verdadeira raça ariana. Para Evola, o [povo] judeu ou o judaico-cristão tem um caráter “dissolvente” [einen „auflösenden“ Charakter]. Seu papel consiste precisamente em "dissolver" o mundo da tradição em um mundo de caos, que, no fim, em sua última fase de desenvolvimento como "mundo moderno", é totalmente dominado pelos judeus por meio de uma vontade de poder abstrata e judaica. Heidegger critica justamente a concepção marxista e abstrata do mundo a que Evola aqui se refere - um mundo que pode ser totalmente manipulado por meio do trabalho, da produção e do controle. A pergunta pela essência do pensamento abstrato e manipulável como um tipo de espírito judaico, secularizado, também pode ser encontrada em ambos os autores após a publicação dos Cadernos negros de Heidegger. A razão disso é um mundo científico e tecnicizado que usa o comunismo e o capitalismo como instrumentos. O ponto de partida do pensamento calculador pode ser encontrado em ambos os autores e, além do mais, em Sócrates, figura que, para Evola, tem uma origem judaico-hebraica. ${ }^{40}$

\section{A mística de Mestre Eckhart como pensamento não-metafísico e o} significado dos Cadernos negros

A mística de Mestre Eckhart como pensamento não-metafísico foi mencionada por Heidegger em sua preleção sobre Hölderlin em 1934/1935. Nessa preleção, Heidegger liga o pensamento de Eckhart ao pensamento inicial e não-metafísico de Heráclito. "Sob o poder do pensamento de Heráclito (...) permanece, indiretamente, no fundamento, o início da filosofia alemã com Mestre Eckhart". ${ }^{41}$

eu estava mesmo inclinado a ver o resultado de uma tática daquilo que eu havia chamado de 'guerra oculta"”.

40 A respeito de Sócrates, Evola escreve: Che $i$ primi rivolgimenti antitradizionalisti, criticistici, antireligiosi e "scientisti" della antica civiltà greca siano stati propiziati o iniziati da Ebrei; che Sócrate fu Ebreo, e Ebrei furono non solo i nominalisti medievali ma anche un Cartesio, un Galileo, un Bacone, e via dicendo. EVOLA, Julius. Tre aspetti del problema ebraico, Milan, 1936, p. 35. [N.T.]: Citação em italiano, no original. "Que as primeiras revoltas antitradicionalistas, críticas, antirreligiosas e "científicas" da antiga civilização grega foram propiciadas ou iniciadas por judeus; que Sócrates era judeu e os judeus não foram apenas nominalistas medievais, mas também Descartes, Galileu, Bacon e assim por diante".

${ }^{41}$ HEIDEGGER, Martin. Hölderlins Hymnen Germanien und Der Rhein, Frankfurt am Main, 1980, pp. 133-134. Em seu seminário conjunto com Eugen Fink sobre Heráclito, no semestre de inverno de 1966/1967, Heidegger diz: “o nome de Heráclito não é o título de uma filosofia grega há muito tempo desaparecida. Tampouco é a fórmula para o pensamento de uma humanidade universal enquanto tal. $\mathrm{Na}$ verdade, é o nome de uma potência originária do ser-aí histórico ocidental-germânico". HEIDEGGER, 
Contudo, na esfera transcendental, uma apreensão originária do eu é descoberta, uma apreensão que está para além do eu enquanto criatura ou do eu "com propriedades”. O eu originário pode ser considerado como um eu não-criado:

\begin{abstract}
Naquele ser, a saber, onde Deus está acima de todo ser e acima de toda diferença, lá estava eu mesmo, aí eu queria a mim mesmo e conheci a mim mesmo para criar esse ser humano. Por isso, eu sou algo originário de mim mesmo conforme meu ser, que é eterno, mas não segundo meu devir, que é temporal. E, por isso, eu sou não-nascido, e, de acordo com o modo de ser não-nascituro [Ungeborenheit], eu nunca posso morrer (DW II, p. 502). ${ }^{42}$
\end{abstract}

Embora a condição de criatura seja constituída por determinações temporais, corporais e múltiplas, sua transcendência implica colocar-se fora de cada uma das determinações substanciais do eu. Ao superar a temporalidade, a corporeidade e a multiplicidade, a dicotomia vida/morte deixa de operar. De acordo com Eckhart, o eu não-criado jamais pode morrer [sterben]. Evidentemente, o que pode morrer é toda concretização do eu não-criado, constituído no interior da linha temporal nascimento/morte. Em contrapartida, a transcendência da condição de criatura significa um modo de ser não-nascituro [Ungeborenheit], que é a condição de possibilidade do aparecimento de um eu criador. $\mathrm{O}$ eu criador é descrito por Eckhart com a expressão querer. $\mathrm{O}$ eu que quer e que é capaz de criar [kreaturhaft-willentliche Ich] se diferencia do eu não-criado, do qual emana uma vontade [Willen] para além de toda e qualquer limitação temporal, corpórea e múltipla como sua própria essência. A respeito da vontade eterna do eu não-criado, lê-se: “em meu nascimento, nasceram todas as coisas e eu fui a causa originária de mim mesmo e de todas as coisas; e se eu quisesse, eu não seria, tampouco todas as coisas; mas se eu não fosse, então 'Deus' tampouco seria" (DW II, p. 503). ${ }^{43}$

Martin; FINK, Eugen. Heraklit, Frankfurt am Main, 1970, p. 246. "Diante da tentativa que se manifesta, vez ou outra, de tentar fazer começar a filosofia moderna com Mestre Eckhart ou no entretempo de Eckhart e Descartes, deve-se manter a posição admitida até agora". HEIDEGGER, Martin. Die Frage nach dem Ding. Zu Kants Lehre von den transzendentalen Grundsätzen, Frankfurt am Main, 1984, p. 98. A respeito do conceito de propriedade em Eckhart, ver: HERNÁNDEZ, Julio. Studien zum religiösethischen Wortschatz der deutschen Mystik. Die Bezeichnung und der Begriff des Eigentums bei Meister Eckhart und Johannes Tauler, Berlin, 1984, pp. 59-84; e BAEZA, Ricardo. Die Topologie des Ursprungs. Der Begriff der Gelassenheit bei Eckhart und Heidegger und seine Entfaltung in der abendländischen Mystik und im zeitgenössischen Denken, Berlin, 2009, pp. 22-27.

${ }^{42}$ Wan in dem selben wesene gotes, dâ got ist obe wesene und ob underscheide, dâ was ich selbe, dâ wolte ich mich selben und bekante mich selben ze machenne disen menschen. Her umbe sô bin ich mîn selbes sache nâch mînem wesene, daz êwig ist, und niht nâch mînem gewerdenne, daz zîtlich ist. Und her umbe sô bin ich ungeborn, und nâch mîner ungebornen wîse sô enmac ich niemer ersterben.

${ }^{43}$ In mîner geburt, dâ wurden alliu dine geborn, und ich was sache mîn selbes und aller dinge; und hoete ich gewolt, ich enore niht, noch alliu dinc enworen niht; und enwaere ich niht, sô enwore ouch, got ' niht. 
Quando emanei de Deus, todas as coisas aí diziam: Deus é; mas isso não pode me salvar, porque, nesse sentido, me reconheço como criatura. Mas no irromper [Durchbrechen], onde estou livre da minha própria vontade e da vontade de Deus e de todas as suas obras e de Deus mesmo, aí eu estou acima de todas as criaturas e não sou nem "Deus" nem criatura, ao contrário, eu sou o que fui e o que continuarei a ser agora e para sempre (DW II, p. 504). ${ }^{44}$

A ideia de superação do Deus pensado no modo metafísico deve ser compreendida com vistas à prioridade eckhartiana de ruptura diante da fluidez. $\mathrm{O}$ movimento de fluidez, portanto, inclui o esquecimento do ser. Contrário a isso, o contramovimento da ruptura implica a tendência a conhecer o eu verdadeiro e originário para além de todas as determinações da criatura. O processo de ruptura pode ser compreendido como conhecimento de si mesmo do eu não-criado enquanto si mesmo. $^{45}$

Se é apenas o conceito de serenidade que oferece resistência à execução da metafísica, que, de acordo com a análise heideggeriana, é realizada no curso do desenvolvimento do pensamento judaico-calculador, então isso deve ser compreendido como o caminho para uma superação autêntica da metafísica. Eckhart seria, portanto, aquele que, de acordo com Heidegger, daria esse "novo passo". ${ }^{46}$

Contraposto ao pensar calculador, que interpreta tudo de maneira causal e interroga sobre seu porquê, há outra forma de pensar na tradição ocidental que precede o surgimento da metafísica. No entanto, essa precedência não é compreendida historiologicamente [historisch], mas ela remete a um tipo de pensar que aparece por meio de um lugar originário, no qual o ser [Sein] e a palavra se unem e são um. A linguagem poética está relacionada a esse tipo de pensamento anterior. Antes [früher] remete à proximidade do pensar com o ser. Em A proposição do fundamento [Der Satz vom Grund], Heidegger analisa o poema de Angelus Silesius sobre a rosa, que transmite

\footnotetext{
${ }^{44}$ Dô ich $\hat{u} z$ gote vlôz, dô sprâchen alliu dinc: got der ist; und diz enmac mich niht scelic machen, wan alhie bekenne ich mich crêatûre. Mêr: om de, durchbrechen, dâ ich ledic stân mîn selbes willen und des willen gotes und aller siner werke und gotes selben, sô bin ich ob allen crêatûren und enbin weder got noch crêatûre, mêr: ich bin, daz ich was und daz ich blîben sol nû und iemermê.

${ }^{45}$ Burkhard Mojsisch descreve o encontro do eu não-criado consigo mesmo da seguinte maneira: "o pensamento de Eckhart (...) penetra no eu como [algo] pura e simplesmente indiferenciado, no eu em sua identidade com a essência de deus, a deidade. Esse eu como deidade não é nenhuma condição à qual se chega (...). O eu, que encontra a si mesmo, se descobre como eu, que não é outra coisa enquanto eu". MOJSISCH, Burkhard. Meister Eckhart. Analogie, Univozität und Einheit, Hamburg, 1983, pp. 139-140. ${ }^{46}$ Ver: WELTE, Bernhard. Briefe und Begegnungen, Stuttgart, 2003, pp. 29-30. "Der mensche ensol niht haben noch im lâzen genûegen mit einem gedâhten gote, wan, swenne der gedank vergât, sô vergât ouch der got. Mêr: man sol haben einen gewesenden got, der verre ist obe den gedenken des menschen und aller crêatûre" (DW V, p. 205).
} 
a mesma mensagem que os sermões de mestre Eckhart em alemão. O poema diz o seguinte:

A rosa é sem porquê; ela floresce porque floresce

Ela não repara em si mesma, não pergunta se alguém a vê.. ${ }^{47}$

Heidegger comenta a relação do poema com Mestre Eckhart da seguinte maneira:

A sentença inteira é construída de maneira assombrosamente clara e concisa, que se gostaria de chegar à ideia de que à grande e autêntica mística pertenceria a nitidez e a profundidade extremas do pensar. Essa é, então, também a verdade. Mestre Eckhart a testemunha. ${ }^{48}$

A serenidade, que está para além do pensar metafísico, não é um mero conceito ao lado de outros dentro do pensamento de Heidegger. No contexto heideggeriano, a serenidade significa, antes disso, a possibilidade de um movimento contra o pensar calculador. O conceito de espera [Warten] e sua radicalização, que é entendida por Heidegger como serenidade, estão indiretamente presentes nas primeiras obras de Heidegger. O conceito de espera [Warten] foi desenvolvido por Heidegger na preleção Introdução à fenomenologia da religião, no semestre de inverno de 1920/21. Não se trata aqui de uma exegese teológica, mas de uma análise da compreensão autêntica da temporalidade. A expectativa [Erwarten] da parousía não tem ponto ou objeto de referência. Logo, espera-se sem expectar, o que é análogo ao primeiro movimento em relação à serenidade do Heidegger tardio. ${ }^{49}$

A concepção metafísica e moderna do ser humano recai em sua interpretação mesma como animal racional. De acordo com essa concepção, o que distingue o ser humano dos demais entes é sua capacidade de pensar. A respeito disso, Heidegger diz: "se o pensar é a distinção da essência do ser humano, então o essencial dessa essência, ou seja, a essência do pensar, só pode ser vista desviando o olhar do pensar". ${ }^{50}$

Em primeiro lugar, não-querer significa ainda um querer, dominado por um não, mesmo que seja no sentido de um não que se dirige diretamente ao querer mesmo e o rejeite. Portanto, não-querer quer dizer rejeitar voluntariamente o querer. A expressão não-querer significa, em segundo

${ }^{47}$ HEIDEGGER, Martin. Der Satz vom Grund, Frankfurt am Main, 1997, p. 56.

${ }^{48}$ Ibid., p. 56.

${ }^{49}$ A respeito do conceito de serenidade no primeiro Heidegger, ver: BAEZA, Ricardo. Die Topologie des Ursprungs. Der Begriff der Gelassenheit bei Eckhart und Heidegger und seine Entfaltung in der abendländischen Mystik und im zeitgenössischen Denken, Berlin, 2009, pp. 74-80. HEIDEGGER, Martin. Unterwegs zur Sprache, Frankfurt am Main, 1985, p. 37. HEIDEGGER, Martin. "Zur Erörterung der Gelassenheit”. Aus der Erfahrung des Denkens 1910-1976, Frankfurt am Main, 1983, p. 38.

${ }^{50}$ HEIDEGGER, Martin. "Zur Erörterung der Gelassenheit". Aus der Erfahrung des Denkens 19101976, Frankfurt am Main, 1983, p. 38. 
lugar, aquilo que pura e simplesmente permanece fora de qualquer tipo de vontade. ${ }^{51}$

Trata-se aqui de um tipo particular de unidade entre passividade (não-querer) [Nicht-Wollen] e atividade (não quero o não-querer), ou de uma instância que está para além da dicotomia passividade/atividade. Em relação à superação da dualidade passividade/atividade, em conexão com o conceito de deixar [Lassen] contido em serenidade [Gelassenheit] e sobre suas conotações supostamente passivas, Heidegger afirma em seu diálogo:

Investigador: $\mathrm{O}$ senhor fala incessantemente em um deixar, de modo que se tem a impressão de que o que ele significa é um tipo de passividade. Não obstante, eu acredito saber que não se trata, de forma alguma, de um deixar deslizar impotente - e deixar as coisas à deriva.

Erudito: Talvez se oculte na serenidade um fazer mais elevado do que todas as ações do mundo e do que todas as maquinações da humanidade...

Mestre: ...tal fazer mais elevado, porém, não é uma atividade.

Investigador: Assim, a serenidade está, caso se possa falar de um estar, fora da distinção entre atividade e passividade...

Erudito: ....porque a serenidade $n \tilde{a} o$ pertence ao âmbito da vontade. ${ }^{52}$

Porque a serenidade não é passível de ser transformada em objeto, não se deve falar propriamente em um "jazer" [Liegen $].{ }^{53}$ A serenidade está, portanto, para além de toda e qualquer limitação espaço-temporal. A serenidade devidamente compreendida não pode ser ganhada nem perdida. Não se trata aqui de uma condição subjetiva entre outras. A serenidade não é uma coisa [Etwas]. Ela se situa [liegt] para além do pensar calculador. Este é essencialmente incapaz de apreendê-la porque sempre pensa na dualidade atividade/passividade:

Mestre: Não devemos fazer nada, senão esperar.

Erudito: Esse é um péssimo consolo.

Mestre: Ruim ou bom, tampouco devemos expectar qualquer consolo, que é o que fazemos quando apenas afundamos na desolação.

Investigador: Pelo que devemos esperar? E onde devemos esperar? Eu quase já não sei onde estou e nem quem sou.

${ }^{51}$ Ibid., p. 39.

${ }^{52}$ Ibid., p. 41.

${ }^{53}$ [N.T.]: Uma justificativa para traduzirmos Liegen por "jazer" é a relação de permanência própria à característica fixa dos predicados dos objetos. Nesse sentido, uma vez que a serenidade não possui propriedades fixas, resultantes do processo de objetivação que retém predicados, não é possível falar em algo como um substrato, isto é, como um suporte no qual propriedades repousariam ou jazeriam como determinações categoriais. Vale também lembrar a etimologia dos termos aqui em jogo: hypokeimenon, termo grego frequentemente traduzido por "substrato material", significa literalmente "coisa subjacente", isto é, "aquilo que subjaz": substância que permanece de algo, as propriedades fixas; a mesma raiz está presente em subjectum, que significa exatamente "aquilo que jaz na base de algo", o que repousa (liegen) em algo. De maneira análoga, com raiz indo-europeia, o termo liegen indica uma permanência, um estar que se situa no âmbito de um estado de coisas, ou seja, aquilo que está em algo ou que pode ser encontrado como propriedade de algo. 
Mestre: Isso todos nós deixaremos de saber a partir do momento em que deixarmos [ablassen] de criar ilusões a nosso respeito. ${ }^{54}$

A desolação [Trostlosigkeit] mencionada não deve ser aqui compreendida como desespero [Verzweiflung], como se a serenidade, por meio da ausência de consolo, assumisse um valor negativo; ao invés disso, ela significa, sobretudo, a superação radical do consolo, na medida em que o consolo só pode acontecer no plano da vontade e é servido pela vontade. Desolação significa aqui, portanto, novamente não-querer, e, por isso, a serenidade se mostra aqui em sua essência. Para habitar a serenidade, não se precisa fazer nada, senão apenas esperar:

Investigador: Mas, quando esperamos, sempre esperamos por algo.

Erudito: Correto; mas assim que apresentamos para nós o que estamos esperando e o levamos ante nós mesmos, já não estamos mais à espera.

Professor: Na espera, deixamos aberto aquilo pelo que estamos esperando. ${ }^{55}$

O ser-aí se desdobra na forma de abertura de um "aí", no qual ele habita. Essa morada do "aí" significa que o ser-aí se comporta em relação a um espaço específico, que representa a totalidade dos entes. Viver "aí", ou seja, nesse "aí", significa encontrarse disposto em uma determinada região existenciária [existenzielle Gegend]. ${ }^{56}$ Em Ser e tempo, obra de Heidegger de 1927, região significa a apreensão da espacialidade autêntica do ser-aí em oposição à compreensão dela como um espaço geométrico. ${ }^{57}$

O silêncio de Heidegger após a Segunda Guerra Mundial a respeito de sua interpretação do nacional-socialismo tem como fundamento suas próprias convicções, essencialmente políticas. Em outras palavras, ele não se posicionou contra o nacional-

${ }^{54}$ Ibid., pp. $42-43$.

${ }^{55}$ Ibid., p. 49.

${ }^{56}$ [N.T.]: O termo existenziell é utilizado aqui para se referir à região ôntica. Trata-se de um termo comumente utilizado em contextos gerais na língua alemã. Nesse sentido, o intuito desta nota é apenas sinalizar a acentuada diferença entre existenziell, termo relativo ao ente, e existenzial, neologismo criado por Heidegger para se referir ao âmbito do ser e geralmente traduzido por existencial na recepção já mais consolidada das traduções de Heidegger em língua portuguesa.

${ }^{57}$ HEIDEGGER, Martin. Sein und Zeit, Tübingen, 2001, § 24. Die Räumlichkeit des Daseins und der Raum. Nesse sentido, escreve Peter Trawny: "Heidegger atribui ao 'judaísmo mundial' um significado 'metafísico', não um 'racial'. Com isso, ele recebe um papel na narrativa filosófica que Heidegger desenvolve, sobretudo, nos anos 1930 e 1940: na 'história do ser'. Em sua perspectiva, Heidegger narra a história apocalíptica de que, no estágio conclusivo do 'esquecimento do ser' ou do 'niilismo', o mundo é ocupado pelo super poder da 'maquinação' (a técnica). A 'diferença ontológica', a relação entre o 'ser' e o 'ente' está alienada, na medida em que o 'ente' recebe primazia incondicional ante o 'ser'. Há ainda apenas uma operação técnica do 'ente'. Contudo, de acordo com Heidegger, essa operação técnica deve ser levada adiante por um particular 'tipo de humanidade': o 'judaísmo mundial'. Esse é 'pura e simplesmente desvinculado' - desenraizado mesmo em sentido existenciário $e$ intelectual - e pode, portanto, assumir a 'tarefa da história do mundo' de completar o 'esquecimento do ser". GANDER, Hans Helmuth; STRIET, Marcus (Hrsg.), Heideggers Weg in die Moderne. Eine Verortung der "Schwarzen Hefte”, Frankfurt am Main, 2017, pp. 65-66. HEIDEGGER, Martin. Zur Erörterung der Gelassenheit. Aus der Erfahrung des Denkens 1910-1976, Frankfurt am Main, 1983, p. 49. 
socialismo porque queria the permanecer fiel até o fim. Não se trata mais de "salvar" Heidegger. A pergunta se Heidegger era um "nazista" se tornou uma pergunta retórica, especialmente após a publicação dos Cadernos negros. Sua interpretação de Mestre Eckhart também tem lugar em um contexto no qual outros autores, dentro da constelação nacional-socialista, situaram Mestre Eckhart para além da tradição judaicocristã.

Recebido em: 26/12/2020 | Aprovado em: 26/12/2020

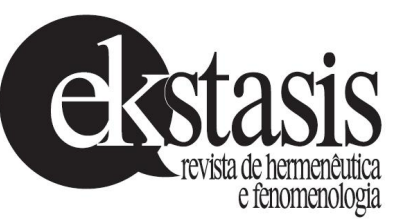

